\title{
A REVIEW ON THE FIFTH PANDEMIC: CORONAVIRUS
}

\author{
KAUR NAVDEEP*, KAUR SIMRANPREET, KAUR MANJINDER
}

Department of Pharmaceutics, Amar Shaheed Baba Ajit Singh Jujhar Singh Memorial College of Pharmacy, BELA (Ropar) Punjab, India. Email: neetudhillon001@gmail.com

Received: 20 September 2020, Revised and Accepted: 16 October 2020

ABSTRACT

Since the 1918 flu pandemic, the novel human coronavirus outbreak COVID-19 has been the fifth known pandemic. COVID-19 was first identified in Wuhan, China, and later spread across the world. It is an infectious disease caused by the coronavirus 2 (SARS-CoV-2) extreme acute respiratory syndrome virus. The patients exhibit flu-like symptoms, including dry cough, sore throat, high fever, and trouble in breathing. Despite too much affords, there is no appropriate treatment or medication which is a successful COVID-19 therapy. A variety of candidate drugs are being used for the treatment and reviewed. This involves clinically accessible medications that are being repurposed for the treatment of COVID-19, such as chloroquine, hydroxychloroquine, and lopinavir/ritonavir. This review describes the different aspects of corona such as history, origin and spread, its types, life cycle, epidemiology, pathogenesis, diagnosis, treatment, and precautions. This review makes us understand what type of virus is this and how we can take precautions to protect us from this life-threatening virus. There is an immediate need to prepare our young generation to fight against any such catastrophe in the future, if any, of science and technology. There is no reason to worry and to fight this epidemic, careful prevention and control are necessary. This article can help to create public awareness, knowledge, avoiding, handling, and treating COVID-19.

Keywords: COVID-19, Virus, Pandemic.

(c) 2020 The Authors. Published by Innovare Academic Sciences Pvt Ltd. This is an open access article under the CC BY license (http://creativecommons. org/licenses/by/4. 0/) DOI: http://dx.doi.org/10.22159/ajpcr.2020.v13i12.39823

\section{INTRODUCTION}

Coronavirus disease (COVID-19) has been a recently discovered coronavirus-caused communicable disease. This disease has become the fifth documented pandemic since the 1918 flu pandemic. The general public infected with the COVID-19 virus will experience mild to moderate respiratory illness and recover with non-special treatment. Coronavirus (CoV) falls within the class of Nidovirales within the genus coronavirus belongs to the family Coronaviridae. The Coronaviridae family could also be divided into Coronavirinae and Torovirinae but may be further categorized into alpha, beta, gamma, and delta. Coronavirus is small in size (65-125 nm in diameter) and contains a single-stranded RNA as a nucleic filament, varying in size from 26 to $32 \mathrm{~kb}$ long [1-3]. Projections on its surface provide with a crown-like appearance under the electron microscope; hence, the term is a coronavirus. Four coronavirus viruses, namely, HKU1, NL63, 229E, and OC43, are in human circulation and typically cause mild respiratory illness. Coronavirus recombination rates are very high because of persistent transcription errors, high mutation rates, and RNA dependent RNA polymerase (RdRP) leaps. The broad scope of COVID-19 extends from moderate, self-limiting tract disease to merciless chronic pneumonia, multiple organ failure, and death. Be fully educated of the COVID-19 virus, the illness it triggers, and the way it progresses is that the only approach to discourage and hamper transmission. The infection is transmitted due to near communication with an infectious individual, susceptible to coughing, sneezing, nasal droplets, or aerosols that spread from humans to humans [4]. Such aerosols may enter the lungs through the nose or mouth through inhalation. Secure yourself from contamination by washing your hands regularly or employing a rub hooked into alcohol, and not touching your face, maintaining a distance from person to person, avoid direct contact with the surface area and wear a mask while going out to public places. After recovery from coronavirus, patients experience seizures as a sideeffect of this disease. It also causes reproductive system issues in both males and females. In males, it leads to a decrease in sperm count, and in females, it causes infertility. They also have to suffer from the bone disorder include osteoarthritis. According to the WHO report, there have been 19,936,210 confirmed cases of COVID-19, including 732,499 deaths, till the date of August 11, 2020, in all over the world [5,6].

\section{HISTORY}

Researchers first described a coronavirus in 1937, isolating one that was to blame for a form of bronchitis in birds with the power to devastate poultry supplies. In 1960, the primary case of coronavirus was reported as cold in human beings. Approximately 500 people were classified as a flu-like condition, consistent with the Canadian report 2001. 17-18 instances of those were reported as polymerase chain reaction contaminated with a coronavirus strain. Before 2002, corona was considered a typical non-fatal virus $[7,8]$. However, as time passes, it had been getting more severe and eventually become the concerned issue. In 2002-2003, when a unique SARS-CoV of the $\beta$ genera induced SARS with a place to begin and reservoirs as bats, transmitted to humans through the conciliator host of civet cats, it contaminated 8422 people in China and metropolis and induced 916 deaths with a rate of 11\%. Therefore, in 2004 the planet Health Organization and disease control and prevention centers proclaimed a "national emergency." A couple of decades later, in 2012, the Middle East coronavirus respiratory syndrome (MERS-CoV), also of bat origin, appeared in the Kingdom of Saudi Arabia with premedical camels because of the host, impacting 2494 people and causing 858 deaths (fatality rate $34 \%$ ). Previously, at the top of 2019, Wuhan, an emerging industrial center in China, witnessed a virus of a unique coronavirus that killed quite eighteen hundred people and contaminated over seventy thousand people during the epidemic's $1^{\text {st }} 50$ days. This virus has been identified as belonging to the $\mathrm{b}$ category of coronaviruses $[9,10]$. COVID-19 was first identified and isolated from pneumonia patent belongs to Wuhan, China. The globe Health Organization (WHO) announced on January 30,2020 , that the COVID-19 epidemic represented a public health emergency of international significance (PHEIC). The Director-General of the WHO proclaimed the COVID-19 epidemic a plague on March 11, 2020 , cantered on the elevated rate of world transmission and also the seriousness of COVID-19 [11,12].

\section{ORIGIN AND SPREAD}

In December 2019, adults in Wuhan, the capital city of the province of Hubei and a significant transportation center of China, started reporting serious pneumonia of uncertain origin to local hospitals. 
China told the WHO about the epidemic on December 31, 2019, and therefore the human seafood shops were closed on January 1, 2020. The virus was identified as a coronavirus on January $7^{\text {th }}$ that has about $95 \%$ similarities with coronary bat virus and about $70 \%$ resemblance to SARS-CoV-2. Samples taken from the things and animals on the Huanan seafood market were also healthy, suggesting that this virus comes from seafood. First, the number of cases began to extend slowly, indicating that transfer from individual to individual happened as a number of these cases was not available within the animal market. The primary cause of fatality was registered on January $11^{\text {th }}$ due to Chinese heavy travel during the Chinese year, which sparked the pandemic [13]. Wuhan's population is about 11 million citizens, where they were held in detention with limits on entry and exit. The virus quickly spread to several cities within the province of Hubei. Certain cases emerged (very fast) in Japan, South Korea, and Thailand, aside from China, on January $23^{\text {rd }}$. Cases began to develop rapidly and tests of models recorded a pandemic doubling time of 1.8 days. Indeed, on Lincoln's Birthday, China, modified the concept of reported cases to incorporate patients with negative/pending molecular tests together with COVID-19 surgical, radiological, and epidemiological characteristics contributing to in rising of 15,000 in at some point in incidents. As of March 05, 2020, 96,000 incidents were registered worldwide $(80,000$ in China) and 87 other countries and 1 overseas travel (696 within the Diamond Princess Ocean liner parked off the coast of Japan). This can be necessary to recollect that although the number of reported cases has recently declined in China; they need dramatically risen in many countries such as South Korea, Italy, and Iran. India, which had recorded just three cases before March 02, 2020, also witnessed a sudden spurt within the incidents. By March 05, 2020, 29 cases had been reported; in Italian tourists and their contacts mostly in Delhi, Jaipur, and Agra [14].

An Indian who traveled back from Wien and revealed a big number of faculty children during a birthday celebration at a city hotel was mentioned in one event. Many of the persons were quarantined for his or her safety and to forestall the spread of the virus. The quantity of reported cases has risen significantly in emerging countries, including Iran, Asian countries, and Italy, although at the identical time, it is beginning to decline in China. COVID-19 incidents in China today have a very cheap development rate relative to other high-profile nations, and also, the epidemic seems to be almost in check [15].

\section{TYPES OF CORONAVIRUS}

The First Human CoVs (HCoVs) was founded in 1965. The type of virus is called CoVs; because of the projection-like surface, which similar to a crown. These CoVs are 26 to $32 \mathrm{~kb}$ lengthen positive-strand RNA viruses. It causes severe respiratory and neurological disease. This CoV contains four genera such as Alpha, Beta, Gama, and Delta. Of 4 genera, alpha and beta produce human respiratory illness.

Coronaviruses belong to the subfamily Coronavirinae in the family Coronaviridae. Different types of human coronaviruses vary in how severe the resulting disease becomes and how far they can spread. Coronaviruses are named for the crown-like spikes on their surface. There are four main sub-groupings of coronaviruses, known as alpha, beta, gamma, and delta [16-18].

Human coronaviruses were first identified in the mid-1960s. Doctors currently recognize seven types of coronavirus that can infect humans. The seven coronaviruses that can infect people are (Fig. 1):

\section{Common coronavirus}

1. 229E (alpha coronavirus)

2. NL63 (alpha coronavirus)

3. OC43 (beta coronavirus)

4. HKU1 (beta coronavirus)

Other human coronavirus

1. MERS-CoV (the beta coronavirus that causes Middle East respiratory syndrome, or MERS)

2. SARS-CoV (the beta coronavirus that causes severe acute respiratory syndrome, or SARS)

3. SARS-CoV-2 (the novel coronavirus that causes coronavirus disease 2019, or COVID-19).

People around the world commonly get infected with human coronaviruses 229E, NL63, OC43, and HKU1. Sometimes coronaviruses that infect animals can evolve and make people sick and become a new human coronavirus. Three recent examples of this are 2019-nCoV, SARS-CoV, and MERS CoV. SARS-CoV-1, MERS-CoV, and SARS-CoV-2 are pathogenic and cause severe infections in humans following contact with the respective intermediate hosts (bats) (Fig. 2). However, HCoV229E, HCoV-NL63, HCoV-OC43, and HCoV-HKU1 do not appear to cause severe infections in humans [19].

\section{LIFE CYCLE OF COVID-19}

SARS-CoV-2 is getting into bind human cells angiotensin-converting enzyme 2 (ACE2). After binding of ACE2, the COVID-19 virus is entered into the cell through endocytosis (Fig. 2). This process is mediated by membrane-bound protease. It is known as transmembrane serine protease 2 (TMPRSS2), which is involved in cleaves the $\mathrm{S}$ protein for membrane fusion. Then, the COVID-19 viral RNA genome is entering into the intracellular compartment. The viral RNA is translated into the encoded structural and nonstructural proteins. The translation of the nonstructural proteins (Nsp1-16), replicas leads to in massive polypeptide chain, in which the $16 \mathrm{Nsp}$ is cleaved. That process is regulated by host cell proteases, COVID-19 main protease, and papainlike protease. On the other hand, the RNA-dependent RNA polymerase (RdRp) is involved in replicate the viral genome. End of this process, many structural and nonstructural proteins (Nsp1-16) are generated. This is accumulated to the endoplasmic reticulum membrane. These are packed in the Golgi apparatus for viral budding. Finally, through the exocytosis process, it targets to another host cell (Fig. 3) [20,21].

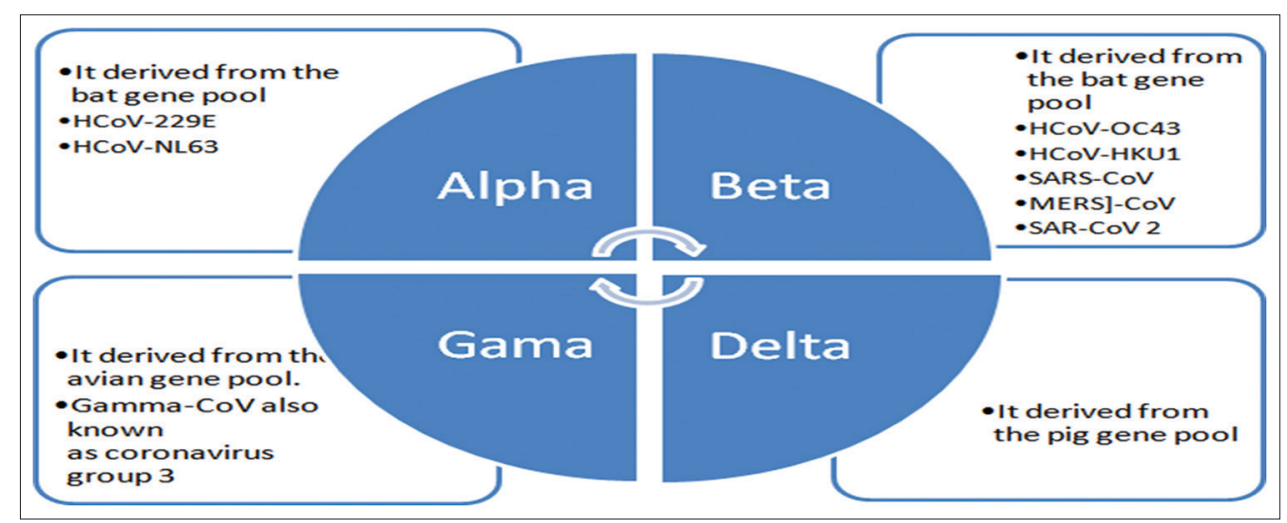

Fig. 1: Coronavirus families are four genera-human respiratory illness producing species (alpha and beta) 


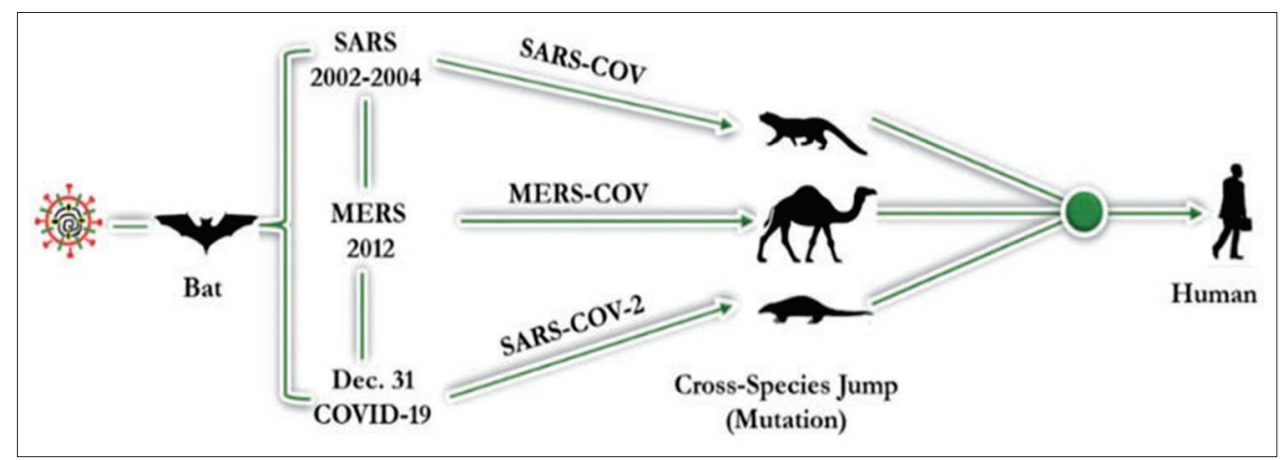

Fig. 2: Mode of coronavirus transmission from carriers to humans

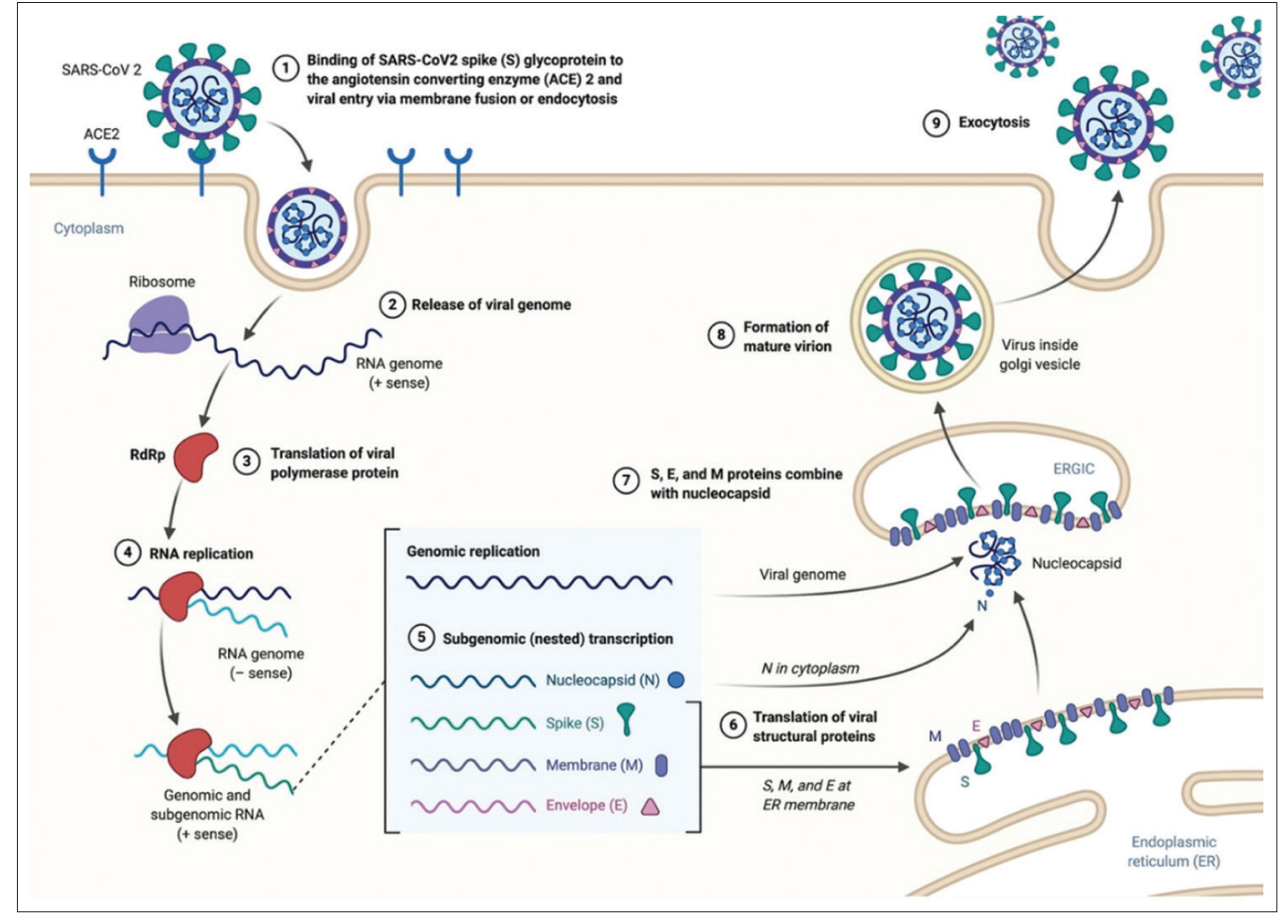

Fig. 3: Life cycle of SARS-COV2

\section{EPIDEMIOLOGY OF COVID-19}

The latest novel 2019 coronavirus disease (COVID-19) that induces pneumonia is a highly contagious illness, and the recent epidemic has infected a large portion of the world's population. It was announced by WHO on January 30,2020 , as a global public health emergency of international significance. From its first epidemic site, Wuhan Area, it is now spreading quickly across Hubei province to other provinces in China and across the world. According to the WHO report, the outbreak is already spreading to over 117 countries as of March 12, 2020. More than 125,048 recorded COVID-19 cases have been detected since the start of the epidemic, and more than 4613 deaths have been documented worldwide. Among these, China reported the bulk (64.8\%) among cases, while the remaining (35.2\%) were found outside China. According to the WHO regular survey, the number of countries registering reported COVID-19 events is now rising periodically [22-30].

Males were most frequently influenced by the novel COVID-19, and the mean age range of patients is 49-59 years. Among adolescents, nearly all recorded incidents existed (median age 59 years). Older individuals are usually twice as prone to severe COVID-19 disease. Slightly more than $2 \%$ of patients were under the age of 18 , of which $<3 \%$ had serious or essential diseases. Based on the analysis conducted by Wu and McGoogan on 72,314 cases in China, COVID-19's average case-fatality rate (CFR) was $2.3 \%$. In such cases, the CFR was higher at 80 and above years of age (8.0\%) and important COVID-19 cases (49.0\%). Furthermore, the CFR was greater for people with preexisting comorbid conditions: $10.5 \%$ for coronary disease, $7.3 \%$ for asthma, 6.3\% for a chronic pulmonary disorder, $6.0 \%$ for hypertension, and $5.6 \%$ for cancer. Notwithstanding far higher CFRs for SARS (9.6\%) and MERS (34.4\%), owing to the vast number of incidents, COVID-19 resulted in more direct deaths. Both ages are susceptible to this lethal virus infection, it is transmitted by symptomatic patients in the process of coughing and sneezing by producing wide contaminated droplets and can disperse between 1-2 $\mathrm{m}$ and deposit on surfaces, but it may also occur from asymptomatic residents until symptoms begin.

As of December 2019, the first reports were registered. Five people were diagnosed with severe respiratory distress syndrome from December 18,2019 , to December 29, 2019, and one of those patients died. By January 2, 2020, 41 hospitals admitted patients had been reported as having COVID-19 infection verified in the clinic, with fewer than half of these patients reporting chronic conditions, including asthma, hypertension, and cardiovascular disease. In that facility, these patients were believed to be contaminated, most possibly due to nosocomial infection by an unexplained mechanism. A disease epidemic that began from a small seafood market has expanded significantly to kill 84,970 people in China and is correlated with 4645 deaths as of June 20, 2020. 
There was a sharp increase in the number of COVID cases in China by February 29, 2020. A drop in the incidence of new incidents, though, continued to fall, contributing to a curve peak for the overall number of cases. The SARS-CoV-2 pandemic has infected 8,525,042 people and claimed 456,973 lives worldwide by June 20,2020 , according to the WHO situation estimates. Until now, the SARS-CoV-2 has been spread to more than 215 countries with disastrous effects in almost all of the world's infected regions identified by the WHO [31].

In a survey involving 425 cases, the mean incubation period was 5.2 days ( $95 \%$ CI $4.1-7.0$ days) and the median incubation period was 3.0 days (range $0-24$ days) in another analysis focused on 1,324 cases. It could be likely that the sole instance, with outlying 24-day incubation duration, was, in reality, a second occurrence rather than a sole cycle of incubation for infection [32].

COVID-19's incubation time is similar to other previous infectious viral diseases-SARS (2-7 days) and MERS-CoV (2-14 days) but is significantly greater than swine flu (1-4 days) and normal influenza (1-4 days). Research analyzing 88 importation cases of travel-related distribution reported a median incubation time of 6.4 days (2.1-11.1 days). The figures typically display a great deal of variation depending on the patient sample type and epidemiological characteristics, although when more evidence is available, more reliable results are expected to appear [33].

At present, October 8, 2020, we have 36,449,272 reported COVID-19 incidents globally, including 1,061,489 deaths, spread as follows: North America: 9,327,415, South America: 8,459,726, Europe: 5,649,656, Africa: 1,546,091, Asia: 11,433,636, and Oceania: 32,027.

\section{PATHOGENESIS OF COVID-19}

The pathogenesis of COVID-19 is still uncertain and could involve the following factors: [34-40]

1. SARS-CoV-2 attaches through the coronavirus spike(S) protein to the angiotensin-converting enzyme-2 (ACE2) receptor to infiltrate alveolar epithelial cells to facilitate immediate toxicity and abnormal immune responses (Fig. 4). The caused systemic inflammation triggers a cytokine outbreak that induces pulmonary damage and people with serious illness evolve and suffer from respiratory failure.

2. Pathological findings revealed that the lungs of COVID-19 patients display diffuse alveolar disruption and hyaline membrane forming in the bloodstream, and lung pathology itself is close to that of SARS and Middle East respiratory syndrome (MERS).

3. ACE2 is also expressed in the kidneys, heart, lung, and intestines, and SARS-CoV-2 may invade cells in the aforementioned tissues to proliferate and destroy these organs resulting in multiple organ dysfunction syndromes (MODS).

4. In patients with severe COVID-19, which may be associated with poor outcomes, the levels of IL-2, IL-6, IL-7, IL-10, granulocyte colonystimulating factor, interferon gamma-induced protein 10 , monocyte chemoattractant protein-1, macrophage inflammatory protein $1 \alpha$, and tumor necrosis factor $\alpha$ are significantly high.

5. Excessive activation of lymphocytes in COVID-19 patients and a rise in pro-inflammatory CCR4+CCR6+Th17 cells facilitate immunomedicated injury, leading to increased intensity of mild disease and

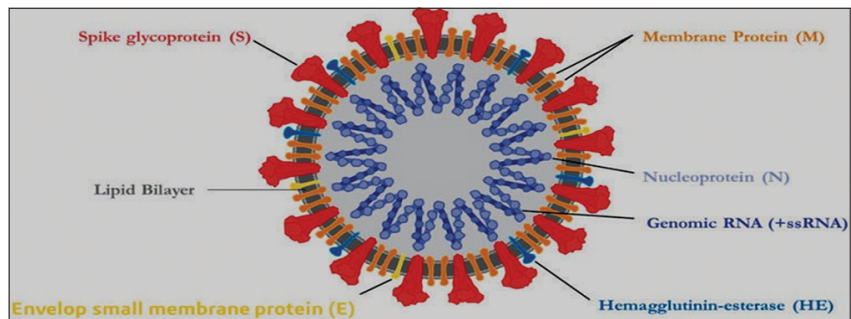

Fig. 4: Structure of SARS-COV-2 progression of single organ involvement to MODS. In particular, elderly people with reduced immunity are more susceptible to infection, and patients with comorbidity.

\section{SYMPTOMS OF COVID-19}

Signs of COVID-19 infection have begun to appear after an incubation period of around 5.2 days. The time from COVID-19 symptoms attack to death ranged from 6 to 41 days, with 14 days average. The incubation period depends on the age of the patient, which is also dependent on the state of the patient's immune system. Patients $>70$ years old have shorter incubation times relative to patients below 70 years old [41-47].

Usually, COVID-19 causes flu-like symptoms such as fever (99\%), chills, dry cough (59\%), sputum (27\%), exhaustion (70\%), lethargy, arthralgia, myalgia (35\%), anxiety, dyspnea (31\%), nausea, vomiting, anorexia (40\%), and diarrhea. Such symptoms may progress into pneumonia, chest pressure, chest discomfort, and breathing problems in the elderly and other patients with other chronic health conditions. It appears as if it begins with a fever and progresses to dry coughing. One week after diagnosis, the symptoms are severe and contribute to reduced breath, with nearly $20 \%$ of patients seeking care and prescription from the hospital. The COVID-19 disorder tends to seldom cause runny, sneezing, or sore throat (only around $5 \%$ of patients have these symptoms). Sneezing the sore cough and stuffy nose are usually common flu or cold signs. A lot of people may experience discomfort or hemoptysis, and others will even be asymptomatic. Mostly, Older people easily effected which are already prone to obesity, coronary disorder. And diabetes [48-51]. Cerebrovascular illness and extreme alveolar injury are more vulnerable to respiratory failure. In extreme situations, the initiation of illness may display accelerated development to organ failure (e.g., acute kidney damage, trauma, acute cardiac damage, acute respiratory distress syndrome [ARDS]), and death. Occasionally patients can experience reduced or high counts of white blood cells, thrombocytopenia, or lymphopenia, with elevated amounts of C-reactive protein and prolonged activated duration of thromboplastin. This is reported that $80 \%$ of affected cases are moderate, with typical fever and flu, so patients will recover at home. In brief, a patient with leukopenia or lymphopenia will be accused of developing upper respiratory tract symptoms and fever [52-56].

\section{DIAGNOSIS}

Diagnosis of suspicious infections should be made as quickly as possible to rapidly identify and monitor the infection. COVID-19 should be considered in any patient with fever and/or lower respiratory tract symptoms with all of the following risk factors in the previous 2 weeks: Near interaction with confirmed or reported cases in any area, especially in healthcare settings without proper protective equipment or long-term status in such settings, and living or traveling from wellknown locations where the disorder is an outbreak. Patients with extreme lower respiratory tract disease without alternate etiologies and a consistent infection history should be considered COVID19 unless otherwise reported $[57,58]$.

To assist with COVID-19 dia0gnosis, clinical signs need to be evaluated. The WHO and the United States Centers for Disease Control and Prevention (CDC) have given preliminary updates on important clinical and epidemiological results of COVID-19. Extensive laboratory testing for confirming COVID-19 diagnosis should be required. RT-PCR can be used in isolated samples with swabs of the stomach, sputum, stool, and blood. Main laboratory admission findings include leukocytes below or beyond the normal range; neutrophils beyond normal range; and lymphocytes, hemoglobin, and platelets below normal range [59].

High levels of alanine aminotransferase, aspartate aminotransferase, C-reactive protein, creatine kinase, lactate dehydrogenase, blood urea nitrogen, and serum creatinine can be the main liver findings. Concerning the infection index, procalcitonin levels can surpass normal ranges [60]. 
Radiological studies can also assist in the diagnosis of virally compromised patients with pneumonia. In over $75 \%$ and $71 \%$ of adult patients, respectively, bilateral and multi-lobe involvement of the lungs was normal. In pediatric patients, the following guidelines for fast respiratory rate should be met for COVID-19 induced pneumonia diagnosis: $\geq 60$ times/min for less than 2 months of age; $\geq 50$ times $/ \mathrm{min}$ for 2-12 months of age; $\geq 40$ times/min for 1-5 years of age; and $\geq 30$ times/min for $>5$ years of age (after removing fever and crying effects) [61-65].

\section{DIFFERENTIAL DIAGNOSIS}

Including viral respiratory infections caused by the SARS virus, influenza virus, parainfluenza virus, adenovirus, respiratory syncytial virus, and metapneumovirus can include a differential diagnosis. These patients have identical clinical characteristics, but in some cases, with increased or reduced leukocyte counts. Patients may also have pneumonia due to bacterial causes that may be caused by high fever and moist rale cough. Another common form of misrepresentation is mycoplasma pneumonia. For such patients, chest X-ray images may show reticular shadows and slight patchy or large consolidations. To this differential diagnosis, mycoplasma-specific IgM is helpful. Epidemiological treatment and the examination of blood or sputum will help to confirm the accurate diagnosis of COVID-19. COVID-19 cannot be isolated from these pathogens either clinically or by regular laboratory examination. Hence, the history of travel becomes significant. The travel past will, thus, become meaningless as the disease spreads $[66,67]$.

\section{TREATMENT}

There is no precise treatment for coronavirus, but prevention, management, and supporting healthcare may provide relief in the outbreak of COVID-19. The first-line treatment is self-quarantining for at least 14 days and the cure is to keep a distance of at least three feet and sanitize yourself after every outing. However, some approaches have been or may be used to control this disease. These approaches may be categorized in Allopathic, Unani, and Homeopathic treatments. Allopathic treatment and management embrace medical care, blood vessel fluid infusion with life support in dangerous cases. It is additionally sensible to contact a healthful professional if the flue like symptoms prevails. In general, the Unani medicines (plant-based medicines) are nontoxic and with none facet effects [68]. Unani and Ayurvedic strategies of the treatment supported the plant materials. The various elements of the assorted plants are acknowledged for a protracted time for his or her anti-viral activities. The most necessary plants are liquorice, Allium cepa, Allium sativum, asterid dicot genus sanctum, asteroid dicot genus tenuiflorum, Madagascar pepper, magnoliid dicot genus verum, Daucus maritimus, turmeric, etc. A liquid extract of those plants in conjunction with juice and honey was found to be effective for contagion and customary cold virus infections. In medical care, arsenic at terribly low concentration is taken into account useful for many diseases together with infectious agent infections. Recently, the board of AYUSH, New Delhi, India, issued an order dater on January 30,2020 , to require prophylactic medication to avoid coronavirus infection. The board steered taking four pills of Arsenic Album-30 medication once daily in the empty abdomen for three days. Arsenic Album-30 is a very diluted arsenic and works as medical aid prevention. It is necessary to say here that there is no clinical proof for Arsenic Album-30 medication as a good medication $[69,70]$.

Establishing a useful medicine against COVID-19 is desperately required. Variety of medication are claimed to be safe and economical by irregular controlled trials; but, solely 2 of that are allowed by government agency therefore far:

At terribly $1^{\text {st }}$ time combination of two medicines was suggested for the treatment for corona that was $200 \mathrm{mg}$ of hydroxychloroquine (3 times daily for 10 days) with $500 \mathrm{mg}$ of azithromycin (only for $1^{\text {st }} 5$ days). However, it does not show any helpful results.
Earlier discovered drugs are used for the treatment of earlier symptoms such as antimalarial drugs salt and anti-inflammatory salt. The subsequent is an outline of the medicine being employed or undergoing trials at present. Once conducting varied tests to see the effectiveness of antimalarial drug salt (CQ) and anti-inflammatory salt (HCQ), they are presently used as first-line treatment medicine in most countries. The antimalarial drug is a previous drug used against protozoal infection that is cheap and safe for elder patients. Consistent with studies, compared with CQ, HCQ has fewer facet effects in semi-permanent use, fewer drug-drug interactions, and may be employed in higher doses. It is attainable that a mix of anti-inflammatory and azithromycin could have a positive result, particularly in severe cases. Despite the effectualness of those two-medicine within the recovery method, there are also some facet effects together with Gi responses, risk of internal organ arrhythmias, and risk of retinal damage, particularly with future use. Remdesivir may be a new medicine being beneath examination that inhibits infectious agent replication through premature termination of ribonucleic acid transcription and is capable of poignant a good variety of ribonucleic acid viruses. Many clinical trials have indicated the potency of Remdesivir within the treatment procedure [71,72].

Other antiviral agents that inhibit the proteinase activity of coronavirus and HIV in vitro or animal model studies are lopinavir (LPV) and antiviral (a nucleoside analog). No variations were determined throughout the infectious agent shedding once treatment with Kaletra (combined drug lopinavir and ritonavir). The European society of medical care medication (ESICM) does not advocate the routine use of Kaletra. Corticosteroids inhibit immune responses and microorganism clearance despite suppressing respiratory organ inflammation. There is no evidence-based reason to contemplate corticosteroids useful within the treatment method; rather, they are a lot of possibilities to be harmful. Interim steerage from WHO on the clinical management of severe acute infection (released March 13, 2020) suggests against the employment of corticosteroids once SARSCoV-2 infection is suspected, apart from exceptional circumstances, particularly severe cases that ought to be prescribed with care. Some medicine is still beneath investigation such as anti-influenza medicine, umifenovir, oseltamivir, and also the helpful treatments for severe acute respiratory syndrome and MERS (the alternative beta coronaviruses that unfold 20 years ago). Researchers are creating a nice effort to search out economical medicine exploitation, irregular management trials necessary before utilization. The worldwide unfold of COVID-19 has become a vital health issue. However, a lot of data is nonetheless to be nonheritable. Public health efforts are most required to limit the occurrence of the virus through human to human transfer, which looks to be the most effective approach within the current state of affairs. Meanwhile, there are no medicines that have been shown to prevent or cure the disease [73]. Recovered patients donated their plasma for the treatment of Covid patients.

To overcome this, coronavirus spread vaccination is important that will help to boost up the immune system against the virus so that we should not become sick. About 140 vaccines are under development and around two dozen are now being tested on people in clinical trials. Till now, only the oxford vaccine shows a good result in triggering the immune response and many countries considered it safe and effective against the virus, but now the preliminary trials of the Oxford AstraZeneca vaccine were temporarily stopped because a volunteer developed neurological symptoms, later found unrelated to the jab. Normally vaccine takes 1-2 years for its development, but due to the severe condition of the world, researchers tried their best to get it as soon as possible all over the world till the mid of the coming 2021 [74].

\section{PRECAUTIONARY MEASURES AGAINST COVID-19}

The degree of COVID-19 spread is currently around 5.3\%, which could theoretically rise if precautionary steps are not taken into account. Consequently, global avoidance of the dissemination of COVID-19 is a critical and immediate priority. The diagnosis and treatment of persons with COVID-19 is a high priority to avoid the further transmission of 
this disease. Self-quarantine, segregation of infectious persons, social distancing, proper personal hygiene (frequent handwashing with soap and water/alcohol-based sanitizers and avoiding touching the eyes, nose, and mouth), and use of personal protective equipment are examples of steps to prevent spreading. Any compound groups, called surfactants, are found in soap and are capable of neutralizing microbes such as SARS CoV2. This is because soap can be shaped into structures called micelles that capture viral matter and other biomaterials that are bubble-like. In soap lather, surfactants have their hydrophilic sections pointed outward and communicating with solvent and pointed inward with their hydrophobic heads. This removes the outer membrane of the coronavirus and encapsulates viral molecules inside micelles, rendering insoluble viral molecules readily soluble in water after around 20 s and easily extracting them from the palms, surfaces, or other regions. Hence, surfactants in the soap can destroy and sequestrate viruses and other pathogens, while sanitizers and disinfectants are intended to kill SARS-CoV-2 [75,76].

\section{CONCLUSION}

The SARS-CoV-2 epidemic has become a threat worldwide. Knowledge concerning this virus, however, remains minimal. The knowledge available is unreliable and data changes are continuous, which can lead to differences with the findings of the analysis. Well-annotated data from hospital cases and subclinical subjects in normal populations might help better explain the pandemic for more reliable and accurate results. The pathophysiology, diagnosis, and possible treatment of SARS-CoV-2 are outlined in the details given in this study. In the search for effective therapies, diagnostics, and vaccines, development activities are being increased to resolve the emerging challenges. Clinical work on the genetic variation of tissue and population-wide receptors such as ACE-2 will remain an ongoing area of study until relevant targets and therapies are identified. Although the production of effective COVID-19 therapies and vaccinations is ongoing, it is recommended to adopt proper health habits, including handwashing and social distancing, and to follow government recommendations. This would lead to reducing the disease's spread. We hope that researchers will be able to help patients build adaptive habits and improve the efficacy of health care professionals with the knowledge learned from this study. Only after this pandemic stops will one be able to determine the health, social, and economic effects of this global catastrophe and we should be able to draw lessons for all potential comparable pandemics, notably in terms of environmental and global health.

\section{AUTHORS' CONTRIBUTIONS}

All the authors contributed equally in compilation and editing and finalizing the review. They all read and approved the final manuscript.

\section{DECLARATION OF CONFLICTING INTEREST}

The authors declare that there are no conflicts of interest.

\section{AUTHORS' FUNDING}

Not applicable.

\section{REFERENCES}

1. Irappa M, Malay S, Nagaveni K. COVID-19: A review. Monaldi Arch Chest Dis 2020;90:248-58.

2. Wang $\mathrm{D}, \mathrm{Hu} \mathrm{B}, \mathrm{Hu}$ C. Clinical characteristics of 138 hospitalized patients with 2019 novel Coronavirus-infected pneumonia in Wuhan, China. J Am Med Assoc 2020;323:1061-9.

3. Monisha B, Manpreet WK. COVID19-an overview of epidemiology, symptoms, prevention, management, treatment, and role of health workers international. J Appl Pharm 2020;12:36-41.

4. Guo YR, Cao QD, Hong ZS, Tan YY, Chen SD, Jin HJ, et al. The origin, transmission and clinical therapies on Coronavirus disease 2019 (COVID-19) outbreak-an update on the status. Mil Med Res 2020;7:11.

5. Angham GH, Mohammed K, Nany H, Emad Y, Salam AM. A review on COVID-19: Origin, spread, symptoms, treatment, and prevention. Biointerface Res Appl Chem 2020;10:7234-42.

6. Hilgenfeld R. From SARS to MERS: Crystallographic studies on Coronaviral proteases enable antiviral drug design. FEBS J 2014;281:4085-96.

7. Cui J, Li F, Shi ZL. Origin and evolution of pathogenic Coronaviruses. Nat Rev Microbiol 2019;17:181-92.

8. Muhammad AS, Suliman K, Abeer K, Nadia B, Rabeea S. COVID-19 infection: Origin, transmission, and characteristics of human CORONAVIRUSes. J Adv Res 2020;24:91-8.

9. Li Q, Guan X, Wu P, Wang X, Zhou L, Tong Y, et al. Early transmission dynamics in Wuhan, China, of novel Coronavirus-infected pneumonia. N Engl J Med 2020;382:1199-207.

10. Tian X, Li C, Huang A, Xia S, Lu S, Shi Z. Potent Binding of 2019 Novel Coronavirus Spike Protein by a SARS Coronavirus-Specific Human Monoclonal Antibody, bioRxiv; 2020.

11. Pengfei S, Xiaosheng L, Chao X, Wenjuan S, Pan B. Understanding of COVID $\square 19$ based on current evidence. J Med Virol 2020;92:548-51.

12. National Health Commission's Briefing on the Pneumonia Epidemic Situation, in Chinese; 2020. Available from: http://www.nhc.gov.cn/ yjb/s7860/202001/9614b05a8cac4ffabac10c4502fe517c.shtml. [Last accessed on $2020 \mathrm{Feb} 23$ ]

13. Tanu S. A review of Coronavirus disease-2019 (COVID-19). Indian J Pediatr 2020;87:281-6.

14. Middle East Respiratory Syndrome Coronavirus; 2020. Available from: https://www.who.int/emergencies/mers-cov/en. [Last accessed on 2020 Feb 16].

15. World Health Organization. Situation Reports; 2020. Available from: https://www.who.int/emergencies/diseases/novel-coronavirus-2019/ situation-reports. [Last accessed on $2020 \mathrm{Feb} 22$ ]

16. Lai CC, Shih TP, Ko WC, Tang HJ, Hsueh PR. Severe acute respiratory syndrome Coronavirus 2 (SARS-CoV-2) and Coronavirus disease-2019 (COVID-19): The epidemic and the challenges. Int J Antimicrob Agents 2020;55:105924

17. Wu Z, McGoogan JM. Characteristics of and important lessons from the Coronavirus disease 2019 (COVID-19) outbreak in China: Summary of a report of 72314 cases from the Chinese centre for disease control and prevention. JAMA 2020;323:1239-42.

18. Ali I, Alharbi OM. COVID-19: Disease, management, treatment, and social impact. Sci Total Environ 2020;728:138861.

19. Million M, Lagiera JC, Gautreta P, Colson P, Fournier PE, Amranea S, et al. Early treatment of COVID-19 patients with hydroxychloroquine and azithromycin: A retrospective analysis of 1061 cases in Marseille, France. Travel Med Infect Dis 2020;35:101738.

20. Gordon CJ, Tchesnokov EP, Feng JY, Porter DP, Gotte M. The antiviral compound remdesivir potently inhibits RNA-dependent RNA polymerase from Middle East respiratory syndrome Coronavirus. J Biol Chem 2020;295:4773-9.

21. Vijayvargiya P, Garrigos ZE, Almeida NE, Gurram PR, Stevens RW, Razonable RR. Treatment considerations for COVID-19: A critical review of the evidence (or lack thereof). Clin Proc 2020;95:1454-66.

22. Naserghandi A, Allameh SF, Saffarpour R. All about COVID-19 in brief. New Microbes New Infect 2020;35:100678

23. Abebe CE, Dejenie TA, Shiferaw MY, Malik T. The newly emerged COVID-19 disease: A systemic review. Virol J 2020;17:96.

24. Gennaro FD, Pizzol DD. Coronavirus diseases (COVID-19) current status and future perspectives: A narrative review. Int $\mathrm{J}$ Environ Res Public Health 2020;17:2690.

25. Madabhavi I, Sarkar MM, Kadakol NN. COVID-19: A review. Monaldi Arch Chest Dis 2020;90:248-58

26. Zhao N, Zhou ZL. An update on the status of COVID-19: A comprehensive review. Eur Rev Med Pharmacol Sci 2020;24:4597-606.

27. Unhale SS, Ansar QB, Sanap S. A review on Coronavirus (COVID-19). World J Pharm Life Sci 2020;6:109-15.

28. Varghese HS. Current review on COVID-19 pandemic: A global perspective. Int J Basic Clin Pharmacol 2020;9:1159-66.

29. Hasnain J, Faisal S, Khan A, Khan S, Usman H, Liaqat R, et al. COVID-19: Review of epidemiology and potential treatments against 2019 novel Coronavirus. Discoveries 2020;8:1-13.

30. Xie P, Ma W, Tang H, Liu D. Severe COVID-19: A review of recent progress with a look toward the future. Front Public Health 2020;8:189.

31. Shirani K, Sheikhbahaei E, Torkpour ZZ, Ghadiri M. A narrative review of COVID-19: The new pandemic disease. Iran J Med Sci 2020;45:233-49.

32. Chatterjee P, Nagi N, Agarwal A, Das B, Banerjee S, Sarkar S, et al. The 2019 novel Coronavirus disease (COVID-19) pandemic: A review of the current evidence. Indian J Med Res 2020;151:147-59.

33. Ahn DG, Shin HJ, Kim MH, Lee S. Current status of epidemiology, diagnosis, therapeutics, and vaccines for novel Coronavirus disease 2019 (COVID-19). J Microbiol Biotechnol 2020;30:313-24.

34. Shi Y, Wang G, Cai XP, Deng JW, Zheng L, Zhu HH, et al. An overview 
of COVID-19. J Zhejiang Univ Sci B. 2020;21:343-60.

35. Parveen F, Hussain M, Ansari N, Arshad Z, Haroon M, Ammar M, et al. A review on COVID-19, symptoms, epidemiology, pathogenesis, and future challenges. Sch Int J Biochem 2020;3:114-7.

36. Singhal T. A review of Coronavirus disease-2019 (COVID-19). Indian J Pediatr 2020;87:281-6.

37. Nicola M, Neillb NO, Sohrabib C, Khan M, Agha M, Agha R. Evidence-based management guideline for the COVID-19 pandemicreview article. Int J Surg 2020;77:206-16.

38. Valencia DN. Brief review on COVID-19: The 2020 pandemic caused by SARS-CoV-2. Cureus 2020;12:e7386.

39. Harapan H, Itoh N, Yufika A. Coronavirus disease 2019 (COVID-19): A literature review. J Infect Public Health 2020;13:667-3.

40. Vaidya MM, Mahendru D, Semwal A, Kaur S, Kaur H, Sarma P, et al. COVID-19 pandemic: A review based on current evidence. Indian J Pharmacol 2020;52:117-29.

41. Pascarella G, Strumia A, Piliego C, Bruno F, Del Buono R, Costa F. COVID-19 diagnosis and management: A comprehensive review. J Intern Med 2020;288:192-206.

42. Wanga L, Wanga Y, Yec D, Liu Q. Review of the 2019 novel Coronavirus (SARS-CoV-2) based on current evidence. Int J Antimicrob Agents 2020;55:105948.

43. Kumar D, Malviya R, Sharma PK. Corona virus: A review of COVID-19. Eurasian J Med Oncol 2020;1-25.

44. Hadi AG, Kadhom M, Hairunisa N, Yousif E, Mohammed SA. A review on COVID-19: Origin, spread, symptoms, treatment, and prevention. Biointerface Res Appl Chem 2020;10:7234-42.

45. Jean SS, Lee PI, Hsueh PR. Treatment options for COVID-19: The reality and challenges. J Microbiol Immunol Infect 2020;53:436-43.

46. Jiang F, Deng L, Zhang L, Cai Y, Cheung CW, Xia Z. Review of the clinical characteristics of Coronavirus disease 2019 (COVID-19). J Gen Intern Med 2019;35:1545-49.

47. Li H, Liu SM, Yub XH, Tanga SL, Tanga CK. Coronavirus disease 2019 (COVID-19): Current status and future perspectives. Int J Antimicrob Agents 2020;55:105951.

48. Moulishankar A, Ramasamy M, Ravichandran S, Gopalasatheeskumar K. Review on COVID-19. Asian J Res Pharm Sci Biotechnol 2020;8:72-83.

49. Shereen MA, Khan S, Kazmi A, Bashir N, Siddique R. COVID-19 infection: Origin, transmission, and characteristics of human Coronaviruses. J Adv Res 2020;24:91-8.

50. Sohrabi C, Alsafib Z, Neilla NN, Khan M, Kerwanc A, Jabir AA, et al. World Health Organization declares global emergency: A review of the 2019 novel Coronavirus (COVID-19). Int J Surg 2020;76:71-6

51. Sun P, Lu X, Xu C, Sun W, Pan B. Understanding of COVID $\square 19$ based on current evidence. J Med Virol 2020;92:548-51.

52. Tomar A, Gupta N. Prediction for the spread of COVID-19 in India and the effectiveness of preventive measures. Sci Total Environ 2020;728:138762

53. Fadaka AO, Sibuyi NR. Understanding the epidemiology, pathophysiology, diagnosis and management of SARS-CoV-2. J Int Med Res 2020;48:1-23.

54. Hashemian SM, Farhadi T, Velayati AA. A review on remdesivir: A possible promising agent for the treatment of COVID-19. Drug Des Devel Ther 2020;14:3215-22.

55. Huang P, Liu T, Huang L, Liu H, Lei M, Xu W, et al. Use of chest CT in combination with negative RT-PCR assay for the 2019 novel Coronavirus but high clinical suspicion. Radiology 2020;295:22-3.
56. Chen $\mathrm{ZM}, \mathrm{Fu}$ JF, Shu Q, Chen YH. Diagnosis and treatment recommendations for pediatric respiratory infection caused by the 2019 novel Coronavirus. World J Pediatr 2020;16:240-6.

57. Jin YH, Cai L, Cheng ZS, Cheng H, Deng T, Fang YP, et al. A rapid advice guideline for the diagnosis and treatment of 2019 novel Coronavirus [2019-nCoV] infected pneumonia. Mil Med Res 2020;7:1-23.

58. Zhu N, Zang D, Wang W, Li X, Yang B. A novel Coronavirus from patients with pneumonia in China, 2019. N Engl J Med 2020;382:72733.

59. Tan W, Zhao X, Ma X, Wang W, Niu P, Xu W, et al. A novel Coronavirus genome identified in a cluster of pneumonia cases. Chin Centre Dis Control Prev 2020;2:61-2.

60. Russell CD, Millar JE, Baillie JK. Clinical evidence does not support corticosteroid treatment for $2019-\mathrm{nCoV}$ lung injury. Lancet 2020;395:473-5.

61. Arabi YM, Mandourach Y, AI-Hameed F, Sindi AA, Almekhlafi GA, Hussein MA. Corticosteroid therapy for critically III patients with middle east respiratory syndrome. Am J Respir Crit Care Med 2018;197:757-67.

62. Stockman LJ, Bellamy R, Garner P. SARS: Systematic review of treatment effects. PLoS Med 2006;3:1525-31

63. Shang L, Zhao J, Hu Y, Du R, Cao B. On the use of corticosteroids for 2019-nCOV pneumonia. Lancet 2020;395:683-4.

64. Jackson LA, Anderson EJ, Rouphael NG, Roberts PC, Makhene M, et al. An mRNA vaccine against SARS-CoV-2-preliminary report. N Engl J Med 2020;383:1920-31.

65. Zhu FC, Li YH, Guan XH. Safety, tolerability, and immunogenicity of a recombinant adenovirus Type- 5 vectored COVID-19 vaccine: A doseescalation, open-label, non-randomized, first-in-human trial. Lancet 2020;395:1845-54

66. Corbett KS, Flynn B, Foulds KE, Francica JR, Werner AP. Evaluation of the mRNA-1273 vaccine against SARS-CoV-2 in nonhuman primates. N Engl J Med 2020;383:1-12.

67. Amanat F, Krammer F. SARS-CoV-2 vaccines: A status report. Immunity 2020;52:583-9.

68. Rockx B, Kuiken T, Herfst S. Comparative pathogenesis of COVID-19, MERS and SARS in a nonhuman primate model. Science 2020;368:1012-5.

69. Graham BS. Rapid COVID-19 vaccine development. Science 2020;368:945-6

70. Gao Q, Bao L, Mao H. Development of an inactivated vaccine candidate for SARS-CoV-2. Science 2020;369:77-81.

71. Smith TR, Patel A, Ramos S. Immunogenicity of a DNA vaccine candidate for COVID-19. Nat Commun 2020;11:2601.

72. Deming ME, Michael NL, Robb M, Cohen MS, Neuzil KM. Accelerating development of SARS-CoV-2 vaccines-the role for controlled human infection models. N Engl J Med 2020;383:e63.

73. Eyal N, Lipsitch M, Smith PG. Human challenge studies to accelerate Coronavirus vaccine licensure. J Infect Dis 2020;221:1752-6.

74. Mello MM, Silverman RD, Omer SB. Ensuring uptake of vaccines against SARS-CoV-2. N Engl J Med 2020;383:1296-9.

75. Trogen B, Oshinsky D, Caplan A. Adverse consequences of rushing a SARS-CoV-2 vaccine: Implications for public trust. JAMA 2020;323:2460-6.

76. Daniel BC, Osae SP, Henao-Martínez AF, Franco-Paredes C, Chastain JS, Young HN. Racial disproportionality in COVID clinical trials. N Engl J Med 2020;383:e59. 